\title{
Appendix B: Catholic University of Leuven $^{1}$
}

\section{Wim Fyen (KU Leuven Research \& Development), Stijn Kelchtermans (Faculty of Business and Economics, KU Leuven) and Milena Slavcheva (European Commission, Joint Research Centre)}

\section{B.1 INTRODUCTION OF THE UNIVERSITY AND ITS REGIONAL CONTEXT}

The Catholic University of Leuven ('Katholieke University Leuven' in Dutch, abbreviated here to 'KU Leuven') is located in Flanders, which is the northern part of Belgium and home to about 6.5 million inhabitants, more than half of the country's 11.4 million population. ${ }^{2}$ It is an innovative and prosperous region in a country whose GDP per capita rose to $€ 38500$ in 2017 compared to $€ 30000$ for the EU28 average. ${ }^{3}$

It should be noted that in the early 1990s, political decisions in Belgium moved the centre of gravity of science and innovation policy from the federal to the community and regional level. For KU Leuven this means that all innovation and education policies are made by Flanders, classified as an innovation leader, while Belgium as a whole is classified as a strong innovator. ${ }^{4}$ The total R\&D intensity in Belgium and Flanders respectively reached $2.49 \%$ and $2.70 \%$ of GDP in 2016, narrowing the gap with the Europe 2020 target of 3\% and being above the EU28 average of $1.94 \%$. The government input for R\&D in Flanders is above the EU28 average (GBARD as \% of GDP): $0.67 \%$ versus

\footnotetext{
1 The (re-)numbering of sections, tables and graphs in this appendix was done by this book's editors, as well as other minor edits to ensure text and format consistency across all appendices B to F.

2 https://statbel.fgov.be/nl/themas/bevolking.

3 https://ec.europa.eu/eurostat/web/products-datasets/-/sdg_08_10.

4 European Innovation Scoreboard at https://ec.europa.eu/growth/industry/policy/ innovation/scoreboards_en.
} 
$0.64 \%$ in 2016 , and rising further to $0.75 \%$ in 2017.5 Belgium also has a relatively highly educated population: $44.3 \%$ of $25-34$-year-olds had completed tertiary education (ISCED 5-8) in 2016, compared to $38.2 \%$ in the EU28. The country has an excellent science base: $12.6 \%$ of the country's scientific publications were among the top 10\% most cited publications worldwide in 2014 (compared to the EU28 average of $11.08 \%$ ). In terms of technological performance, Flanders occupied ninth position in terms of the number of European Patent Office patent applications per million inhabitants in 2012 compared to a reference group of countries that jointly account for $95 \%$ of global patenting activity. ${ }^{6}$ Fifty-seven per cent of Flemish companies were 'innovative' in the period 2012-2014 according to the Eurostat definition.

KU Leuven was founded in 1425 and is one of the oldest research active universities in Europe. In 2017, it had about 57000 registered students (of which $17 \%$ are international), which makes it the largest in Belgium. It has about 12000 staff members complemented by some additional 8000 full time equivalent staff in the university hospital. It is a comprehensive, research intensive university encompassing 16 faculties that are organised in three groups: Science \& Technology, Biomedical Sciences, and Humanities \& Social Sciences.

KU Leuven forms a network with five university colleges across Flanders and Brussels in the 'KU Leuven Association'. This Association was founded in 2002 in response to the Bologna Declaration of 1999, which sought to increase synchronisation of higher education systems in Europe. Its university colleges account for some additional 50000 students distributed over 21 campuses. In total the KU Leuven Association represents about $42 \%$ of the total Flemish student population. Its members exchange expertise and pool resources, with the aim of improving the quality of teaching and research.

As reported in more detail in section B.4, KU Leuven is not only an important contributor to Belgium's scientific performance as far as the quantity of scientific output is concerned, but it also excels in terms of quality. In line with the innovative performance in the business sector, KU Leuven was named Europe's most innovative university based on the Reuters ranking of 2016, 2017 and 2018. As the highest-ranked Belgian university, KU Leuven has been ranked 48th in the Times Higher Education ranking 2019, and has been consistently among the top 50 research active universities in the world over recent years.

5 Vlaamse Speurgids, 2018 at //www.vlaanderen.be/publicaties/speurgids -ondernemen-innoveren-2018-het-vlaamse-overheidsbudget-voor-economie -wetenschap-innovati.

6 Vlaams Indicatorenboek, 2018 at https://www.ecoom.be/assets/232. 


\section{B.2 REGIONAL ORIENTATION, STRATEGIC DEVELOPMENT, AND KNOWLEDGE INFRASTRUCTURE}

KU Leuven has forged strategic partnerships with many actors in the Flanders region, as well as worldwide, yielding collaborations at various levels, from the local and regional to the national and international.

Locally, the university regularly consults with its stakeholders, such as the Leuven-based nanoelectronics centre ( $\left.\mathrm{IMEC}^{7}\right)$ and the city council members of its hometown, the city of Leuven. This regular consultation led to the creation of Leuven.inc ${ }^{8}$ in 1999, which was consolidated in 2016 through the establishment of the 'Leuven Mindgate'9 initiative to promote the city's regional branding. KU Leuven has also built strong ties with several other cities including Genk and Kortrijk, allowing the university to extend its network of science parks and incubators. There are also very intense collaborations within Flanders in order to promote the region as a knowledge hub towards foreign companies, via an initiative called 'Flanders Smart Hub'. ${ }^{10}$ Setting up networks like these helps speed up the 'Brownian motion' process that results in serendipitous connections, as other successful university-based clusters - such as the one in Cambridge ${ }^{11}$ - have demonstrated.

At the Flemish government level, the university collaborates with most agencies relevant for science and innovation support and policy, such as Flanders Innovation \& Entrepreneurship (VLAIO), Science Foundation Flanders (FWO), the Department of Economy, Science and Innovation (EWI), Flanders Investment and Trade (FIT) and the regionally embedded government innovation centres.

Within the broader region, KU Leuven is actively involved in cross-border collaborations, such as ELAt, a network linking the knowledge regions of Eindhoven, Leuven and Aachen, forming an advanced technological Euroregion.

At the European level, several KU Leuven research centres collaborate with Flemish spearhead clusters - large-scale Triple Helix initiatives addressing strategic domains which receive public support for ten years - and internationally prominent research groups.

\footnotetext{
https://www.imec-int.com/en/home.

https://www.leuveninc.com/.

https://www.leuvenmindgate.be/.

https://www.smarthubvlaamsbrabant.be/international/.

http://www.cambridgephenomenon.com/.
} 
Scientifically, KU Leuven plays a key role in connecting the regional innovation system to international networks. To illustrate, as shown in Figure B.1, the number of scientific publications with international co-authors has increased from about 2500 in 2010 to 4000 in $2015(+60 \%)$ and these international co-publications account for a growing share of the university's scientific output, reaching two-thirds in 2015.

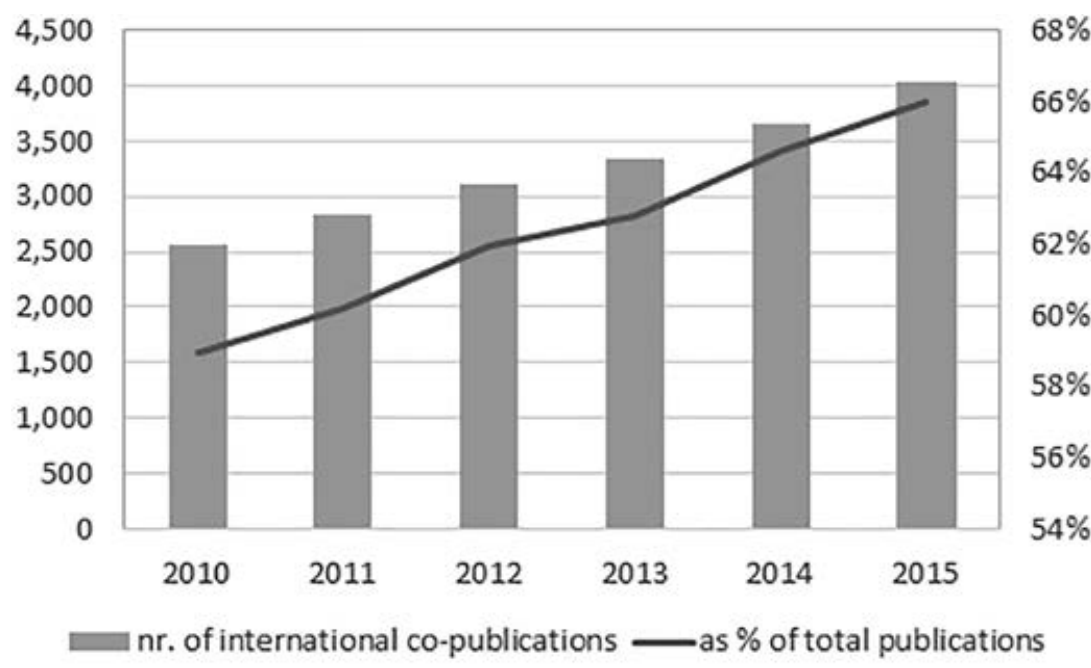

Note: $\quad$ The number of international co-publications counts those KU Leuven publications with at least one other country (besides Belgium) among the affiliations of the co-authors. The curved line indicates the number of international co-publications of KU Leuven divided by its total number of Web of Science publications (of the types Article, Note, Letter or Review) in the respective year.

Source: $\quad$ InCites Dataset (data exported 11 July 2018).

Figure B.1 Scientific publications with international co-authors

At the institutional level, KU Leuven is actively engaged in several international networks, such as the Health Axis Europe, ${ }^{12}$ a strategic alliance with the biomedical clusters in Heidelberg (Germany), Maastricht (Netherlands) and Copenhagen (Denmark). KU Leuven also actively participates in professional associations on knowledge transfer such as Proton-ASTP ${ }^{13}$ and AUTM. ${ }^{14}$ The

12 https://www.health-axis.eu/.

13 https://www.astp-proton.eu/.

14 https://autm.net/. 
university is a founding member of academic networks such as CESAER ${ }^{15}$ and LERU $^{16}$ which serve not only as meeting places to exchange best practices among peers, but also as places to engage in policymaking at the EU level.

KU Leuven is a very active participant in the Knowledge and Innovation Communities (KIC), which are partnerships of businesses, research centres and universities established by the European Institute of Innovation and Technology (EIT) via a competitive application procedure. KU Leuven has typically contributed to these KICs through clusters around its research activities. As an example, KU Leuven Materials Research Centre (LMRC, ${ }^{17}$ an interdisciplinary initiative on materials research) has since 2015 taken an active role in the KIC Raw Materials, while the Leuven Medical Technology Centre (LMTC, ${ }^{18}$ combining engineering sciences and biomedical sciences) was from the start actively involved in the KIC Health. The same goes for KU Leuven's initiative in clustering Flemish energy-related research into the joint research centre Energyville, ${ }^{19}$ which has taken a leading role in the KIC InnoEnergy and for the KU Leuven Food and Nutrition Research Centre (LFoRCe ${ }^{20}$ ) which is actively involved in the FoodConnects consortium that was selected by the EIT to manage KIC Food.

\section{B.3 EDUCATION AND HUMAN RESOURCES DEVELOPMENT}

One of the strategic objectives of the university's technology transfer office is to deepen and support a culture of innovation and entrepreneurship. This is evidenced by a variety of voluntary training initiatives that help to instil an entrepreneurial mind-set among staff, such as a residential three day master class in entrepreneurship ${ }^{21}$ and a modular five day training programme on research valorisation for doctoral and post-doctoral researchers. ${ }^{22}$

Internationalisation is also an important part of the university's human resources development policy. For instance, foreign experience is taken into account in hiring and tenure decisions for new faculty members.

In 2016, KU Leuven set up a Student Career Centre (SCC) which acts as a one-stop shop for all career- and employment-related matters for its students.

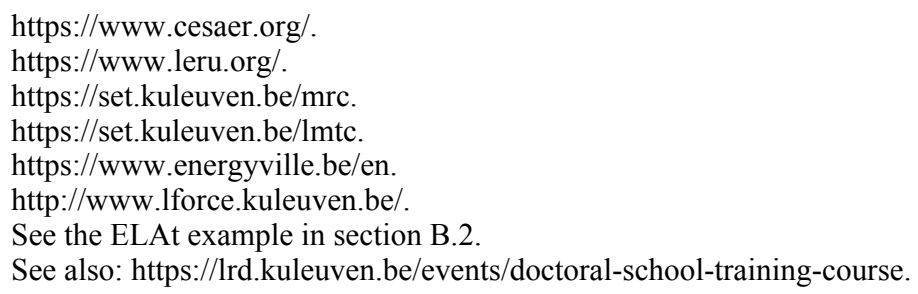


Being the largest university in Belgium, KU Leuven has a profound impact on regional employment. A survey ${ }^{23}$ amongst its recent master students held in 2014-2015 indicates that $83 \%$ find a job in less than three months and more than $98 \%$ in 12 months. About half (51\%) of the recent graduates are employed in the private sector, $32 \%$ in government and $13 \%$ in the health/welfare/sociocultural sectors.

Within the SCC, the Leuven Community for Innovation driven Entrepreneurship (Lcie, addressed in detail in section B.3) has responsibility for all entrepreneurship-related matters. When it comes to bringing entrepreneurship within the educational system, a variety of programmes have been implemented:

- A first set of activities deals with improving entrepreneurial skills: over recent years, various KU Leuven faculties have introduced courses on entrepreneurship both in the master- and bachelor-level curriculum. A portfolio of entrepreneurship courses based on these new courses is managed by the Lcie Academy - an interdisciplinary working group of professors lecturing in entrepreneurship - providing a certificate of entrepreneurship for students participating in the Lcie Academy. The portfolio is created such that students are required to take a variety of courses from different faculties, thereby promoting interdisciplinarity as one of the core values of innovation-driven entrepreneurship. Next to the Lcie Academy courses, other tracks, including a postgraduate entrepreneurial degree for engineering students as well as a Major in Entrepreneurship for business students was established. In the 2017-2018 academic year, more than 1000 students participated in one or more of the Lcie Academy courses, in the postgraduate degree for engineers and/or in the Entrepreneurship Major (equalling some $1.75 \%$ of all registered students).

- A second set of activities focuses on how to leverage initiatives that originate within the Lcie community. These new initiatives often start as an extracurricular activity, but when successful, they may find their way into the official curriculum for certain study programmes. In such cases, the Lcie Core team assists in this transition process. A first example is the course 'Product Innovation Project' $\left(\mathrm{PiP}^{24}\right)$ that was created by a group of students. It is based on a project-based learning format, whereby a multidisciplinary team of students develops a solution to a given problem, delivering a prototype and business case. The concept found its inspiration from

${ }^{23}$ https://www.kuleuven.be/onderwijs/onderwijskwaliteit/bevragingen/ alumnibevraging.

$24 \mathrm{http} / / /$ pipleuven.lcie.be/en/. 
similar initiatives developed at Aalto University ${ }^{25}$ and Graz University of Technology ${ }^{26}$ and was started at KU Leuven with three faculties that offered this course to their students. After four years of operation, the concept has been accepted in 14 (out of a total of 16) faculties. Noteworthy is the support from the faculties in bringing this format into the curriculum. For example, the faculty of engineering science has created a new course descriptor for PiP, that allows students to fully embed this project in their curriculum. This approach is now followed by several other faculties, demonstrating how bottom-up initiatives can become drivers of curricular change.

- In addition, several initiatives were developed by the student and academic community providing valuable support for entrepreneurial projects. A noteworthy example is IusStart, which is a legal clinic initiated in 2014 by $\mathrm{PhD}$ students from the faculty of Law, whereby students provide legal advice for start-ups. At present, the concept has been fully incorporated by the faculty of Law in the form of a master's thesis for law students. Every academic year, some 10-20 IusStart law students provide (as part of their master's thesis) legal advice to some 5-10 start-ups supervised by several PhD students and a number of law offices. Along similar lines, the 'TechStart' concept was initiated recently by $\mathrm{PhD}$ students from the engineering faculty, whereby engineering students provide technology advice to start-ups, thereby receiving ECTS credits.

\section{B.4 RESEARCH, TECHNOLOGICAL DEVELOPMENT, AND KNOWLEDGE TRANSFER}

In 2018, KU Leuven registered $€ 1002$ million of revenues and $€ 953$ million of expenditures. Research expenditures accounted for $€ 476$ million, comparable to the expenditures of $2017 . .^{27}$

Research excellence is illustrated by the number of Web of Science publications (co-)authored by KU Leuven researchers, which has been increasing steadily over recent years, amounting to 6102 in 2015 (Incites data). ${ }^{28}$ Over

\footnotetext{
http://pdp.fi/.

http://product-innovation.at/.

KU Leuven, 2018 annual report.

28 If both the Web of Science (SCIE, SSCI, AHCI, Proceedings) and Flanders' Academic Bibliographic Database for the Social Sciences and the Humanities are taken into account, scientific output rose to about 8800 peer-reviewed publications in 2014-2015. These publications comprise journal articles, monographs, book chapters and conference proceedings (KU Leuven, 2017 annual report).
} 
the 2007-2016 period, KU Leuven published 47742 publications in the WoS database's SCI index, which attracted 901262 citations (accounting for 42.9\% of all citations received by scientific publications in Flanders). Over the same time period, 6269 papers were published in the social sciences and humanities (SSCI and A\&HCI citation indexes in the Web of Science database), attracting 39741 citations in the SSCI-index, or $43.7 \%$ of all SSCI-citations in Flanders. About $3 \%$ of the university's publications are in the highly selective top $1 \%$ of the worldwide citation distribution and its normalised citation impact indicator was 1.7 in 2015, showing that the university's international impact is clearly above average. ${ }^{29}$

Furthermore, KU Leuven awarded 802 doctoral degrees in 2016-2017, of which $44 \%$ were awarded to non-Belgian researchers. The university also performs among the very best at European level, with 107 ERC $^{30}$ Grantees (including affiliates with $\mathrm{VIB}^{31}$ and Imec and incoming ERC-grantees) of which 55 were Starting Grants. KU Leuven participated in over 540 projects in the 7th Framework programme (2007-2013), ranking sixth in the league of higher education institutions. In Horizon 2020, KU Leuven maintains its sixth position with regard to participation, having had 260 projects approved, worth $€ 145.9$ million. The university also attracts international research talent: in 2017,33 of the 89 newly hired professors (37\%) were non-Belgians.

KU Leuven Research \& Development (LRD) was established in 1972 as one of the first technology transfer offices in Europe with a mission to support the university staff in all aspects of research exploitation. Starting from the excellent science base at KU Leuven, LRD has developed a solid tradition of collaborating with industry, securing and licensing intellectual property rights, and creating spin-off companies. The support is given by a multidisciplinary team of over 100 experts who guide researchers in their interactions with industry and society, and help them to best leverage the societal and economic potential of their research. LRD is set up as a separate business unit within the university and plays a constructive role in the development of innovation policy in Flanders as well as in Europe. It actively collaborates with the government, amongst others with respect to the new cluster policy of the Flemish government, the grand challenges, smart specialisation, Horizon 2020 and the other European policy instruments.

29 A normalised citation impact score of 1 equals world average in the respective field of science; KUL is $70 \%$ above world average (data source: InCites Dataset in 2015).

30 European Research Council (http://erc.europa.eu/).

31 Vlaams Instituut voor Biotechnologie, Flemish Biotech Institute (http://www.vib .be/en/Pages/default.aspx). 
A first important role of LRD is to manage all research collaboration agreements between the KU Leuven Association and industry, varying from small consulting assignments commissioned by a company to long-term research projects. Figure B.2 shows the number of new agreements (excluding Material Transfer Agreements and Non-Disclosure Agreements) that are drafted by LRD every year. It is evident from the figure that these activities have significantly increased over the last decade and have not been influenced in a major way by the financial-economic crises.

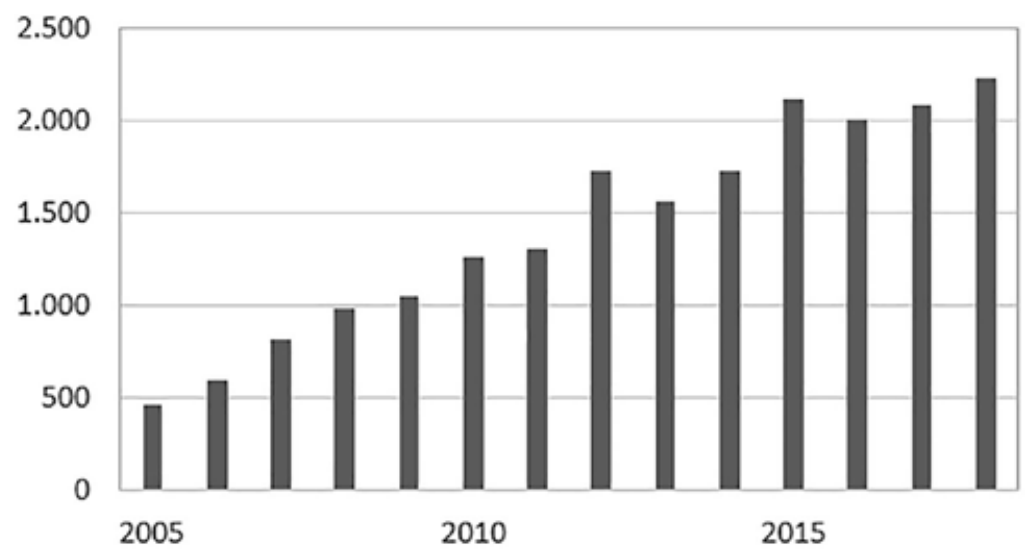

Note: Excluding Material Transfer Agreements and Non-Disclosure Agreements that are being drafted by the university technology transfer office.

Source: Annual reports KU Leuven.

Figure B.2 Yearly number of new agreements

LRD's second activity is the commercialisation of the intellectual property of the KU Leuven Association, which requires an appropriate transfer strategy to ensure that innovation from research at KU Leuven finds its way into society. Figure B.3 shows the number of reported inventions ('new invention disclosures') as well as the resulting number of patent applications at the patent family level. ${ }^{32}$ LRD has an active policy of licensing its intellectual property. In 2017, a total of 56 new licences on KU Leuven intellectual property were signed. This amount is comparable to licensing results from previous years

32 To avoid an inflated measure of patenting activity, the figure reports patent families rather than individual patents as some cases may warrant multiple patent applications for the protection of a single invention. 
and includes licences and transfers on patents, patent applications and other intellectual property such as software, designs, and databases. Besides these two main activities, LRD also actively supports the start of new ventures (spin-offs) and the creation of science parks. Both items are discussed in more detail in section B.5.

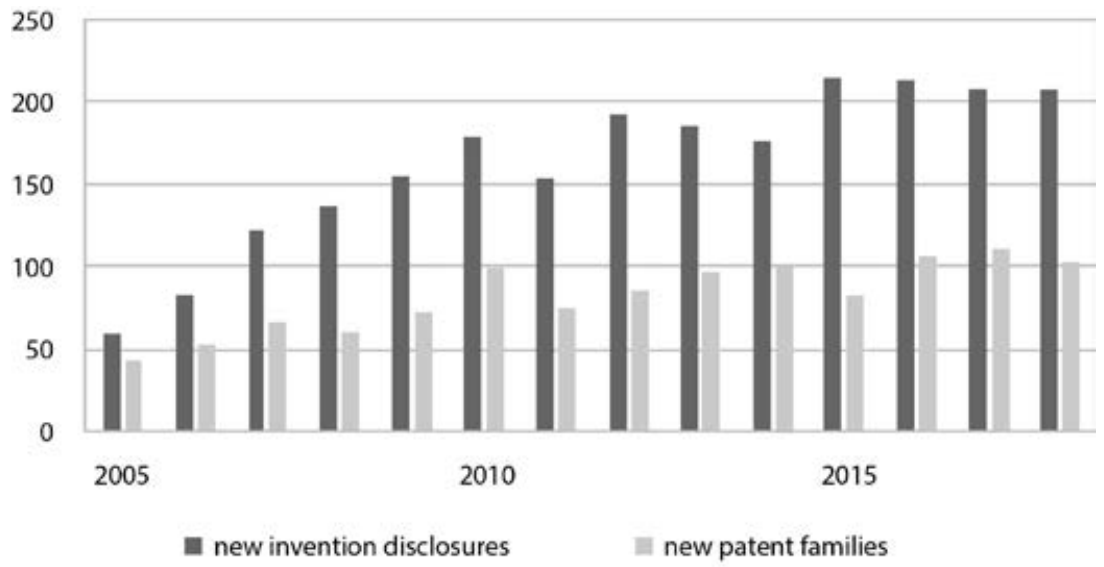

Source: LRD brochure 2018.

Figure B.3 Number of new invention disclosures as well as the resulting number of patent applications at the patent family level

Flemish legislation stipulates that in case of exploitation of an invention the inventors are entitled to a fair share of the proceeds. This provides the possibility to create strong incentives for inventors to collaborate actively with LRD. For that reason, a flexible mechanism to manage these incentives was set up in the form of 'divisions'. The academics responsible for these divisions can invest the money they earn within the divisions, for example for hiring staff, for setting up a patent portfolio or for investing in spin-off companies. Since these investments are made with proceeds from other valorisation activities, academics tend to manage their operations carefully and allocate their resources efficiently. Some divisions act as expertise centres, which take on the role of bridging the gap between scientific work and commercialisation via consultancy activities. This creates a cohort of people with the appropriate skill set to advise businesses and, potentially, set up their own ventures.

The system of 'divisions' at KU Leuven is managed separately from the organisational structure of the university. They act as virtual, often inter- 
disciplinary, companies within the university and are maintained by LRD, independently from the central administration. This activity has reached a sizable scale with about 80 such divisions having been set up. Examples are INCENTIM (International Centre for Research on Entrepreneurship, Technology and Innovation Management), Rega Institute for medical research, ${ }^{33}$ PMA (Production engineering, Machine design and Automation), MICAS (Micro Electronics and Sensors), COSIC (Computer Security and Industrial Cryptography) and DistriNet (distributed systems).

One of LRD's main operational objectives is to create financial leverage effects in order to support and further develop external funding that can complement within-university financing. Besides Flemish and federal funding, these efforts also explicitly target international funding sources and have contributed to KU Leuven's sixth position in the ranking of Horizon 2020 funding recipients, its participation in four KICs (see section B.2) and in international programmes of institutions like the United States National Institutes of Health (NIH), the Wellcome Trust, and the Michael J Fox Foundation. By accessing these international funding channels, the university and the Flemish research and innovation system as a whole becomes further embedded in international R\&D networks, which opens up new paths for research valorisation. In addition to the government and non-profit-related funding streams, KU Leuven is actively involved in setting up bilateral partnerships with the private sector which also adds significantly to this leverage effect. The total revenue of all valorisation activities supported by LRD increased to about $€ 210$ million in $2018,{ }^{34}$ roughly a threefold increase since 2005 . Part of this revenue is used by academics to hire suitable $R \& D$ and support staff to sustain the valorisation activities. This is illustrated in Figure B.4, which shows that in 2018 more than 2500 employees were paid from the revenues ${ }^{35}$ of valorisation activities alone, being a fourfold increase since 2005 .

The university has also set up several platforms that bring researchers and business practitioners together on certain themes such as materials science (LMRC), medical technology (LMTC), food and nutrition (LFoRCe), and drug discovery $\left(\mathrm{CD}^{36}\right)$.

\footnotetext{
33 Named after the 18th-century philanthropist and professor Josephus Rega.

34 There is a decrease in revenue starting in 2017 as a result of a reduction in licensing revenues due to the expiration of the patent on Tenofovir, a drug that has been commercialised in collaboration with Gilead Sciences.

35 The decrease in revenue in 2017 is largely related to a reduction in licensing revenues due to the expiration of the patent on Tenofovir, a drug that has been commercialised in collaboration with Gilead Sciences.

36 Centre for Drug Design and Discovery (http://www.cd3.eu/).
} 


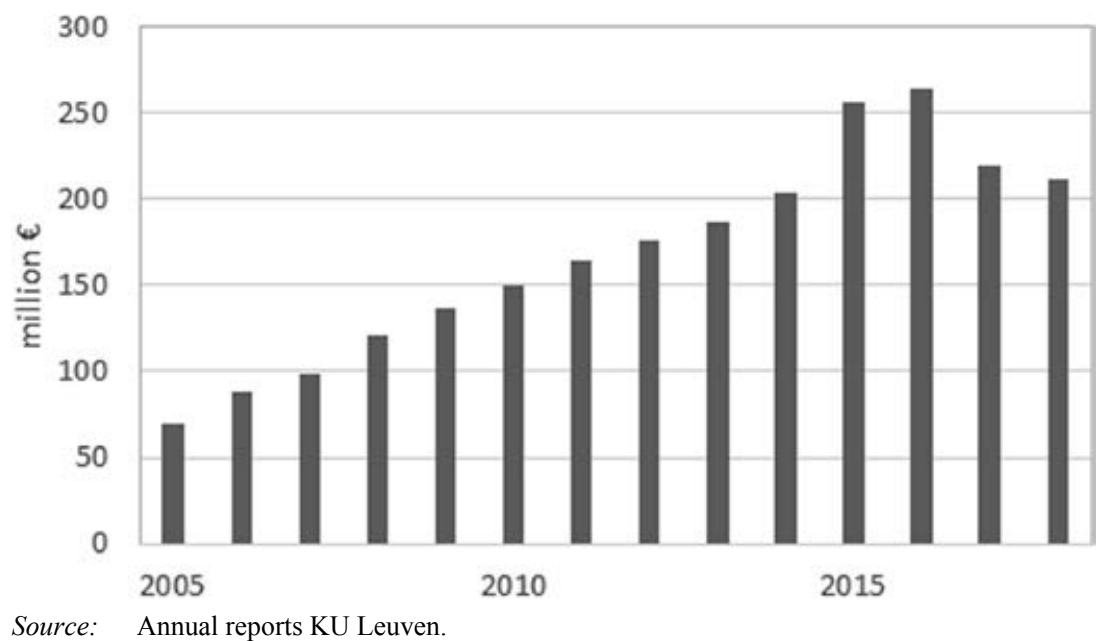

Figure B.4 Yearly total revenue of all valorisation activities supported by $L R D$

\section{B.5 ENTERPRISE DEVELOPMENT AND ENTREPRENEURSHIP}

The support for venture creation at KU Leuven is based on a combination of decentralised attention towards entrepreneurship combined with a strong central support system. As indicated in the next section, a variety of funding schemes exist for researchers to bring their research closer to the market. In addition, the central support for and communication about impact that is reached with valorisation activities lowers the perceived barrier for entrepreneurial behaviour with researchers willing to engage in entrepreneurship. In the period 1979-2017, 124 spin-off companies were founded, of which 99 were still active at the end of 2017, as illustrated in Figure B.5.

One of the key success factors of KU Leuven's enterprise development activities is the availability of complementary incubation funding instruments. They allow researchers to move up their research on the Technology Readiness Level (TLR) scale in order to bring it to a marketable product or service. The most important instruments are:

- The Industrial Research Fund (IOF), set up by the Flemish Government in 2004 in order to 'bridge the gap' between research and application. The fund serves all five universities in the Flemish community and has increased from $€ 10$ million in 2005 to about $€ 32$ million in 2018 and 


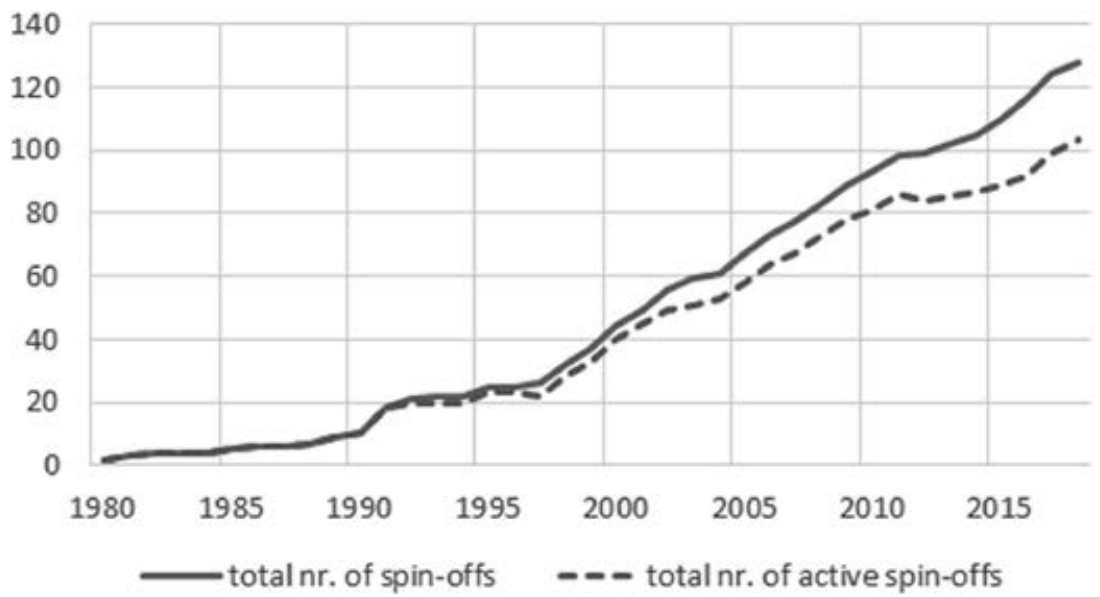

Notes: KU Leuven (solid line) and total number of spin-offs that are still active (dashed line). A spin-off is a legal entity of which the university has become a shareholder as a result of a contribution of its intellectual property (licence of transfer). Besides spin-off companies, several other entities are created with a link to the university, but these are not counted as spin-offs.

Source: $\quad$ LRD brochure 2018.

\section{Figure B.5 Total number of spin-offs}

a further large increase of $€ 20$ million in 2019. These funds are distributed over the Flemish universities and their associated university colleges according to a set of measurable performance indicators, including industrial contracts, EU projects, patents, and spin-offs. Based on these parameters, the share of KU Leuven in the overall IOF funding amounts to $46 \%$, totalling about $€ 15$ million in 2018 . This is used for two types of funding schemes: mandates (i.e. the funding of research managers that are structurally embedded in a research group) and competitive project-based funding. KU Leuven currently has about 35 such 'IOF research managers' and starts some 30 valorisation-oriented projects each year.

- The Gemma Frisius Fund (GFF) is a seed capital fund that was established in 1997 as a joint venture between KU Leuven and the banks KBC and BNP Paribas Fortis. The objective of the fund is to stimulate the creation and growth of KU Leuven spin-off companies. Over the years, the GFF has invested in $51 \mathrm{KU}$ Leuven spin-off companies and since 2009 it operates as an evergreen fund. Noteworthy is also that in the period 2005-2018, KU Leuven, including its venture capital fund (GFF), invested $€ 38.5$ million in its spin-offs, while third-party investors matched this with $€ 1054$ million, generating a leverage effect of about 30:1. 
- The Centre for Drug Design and Discovery (CD3) brings expert drug discovery capabilities and financial means to academic research groups and small companies in order to translate innovative research into promising drug discovery programmes that are well qualified for further development by pharma or biotech companies or by setting up a spin-off company. Supported by LRD and the European Investment Fund, CD3 launched a $€ 60$ million fund in 2016.

- Over recent years KU Leuven has also set up an elaborate set of partnerships and participations as a co-investor in a variety of venture capital funds in domains that are relevant for its activities, such as life sciences, advanced manufacturing, chemistry, materials, and ICT. This allows to further support the growth of the Leuven ecosystem in general and more specifically of its portfolio of spin-off companies.

While so far most emphasis on spin-off creation has been on academic research-based ventures, many universities have also started to focus on student-led ventures. ${ }^{37}$ Along these lines, KU Leuven launched Lcie, the Leuven Community for Innovation driven Entrepreneurship, in 2014 (see also section B.2). It is largely managed bottom-up with significant student involvement throughout its governance system and supported by a small team that is embedded within the TTO, ensuring the necessary autonomy to operate.

In its first years of operation, Lcie has evolved into a university-wide 'brand' for student entrepreneurship with a diverse set of stakeholders. It is financed through a mix of funding sources and was jump-started with small structural funding from the TTO (including in-kind support via a part-time coordinator) and a yearly allowance of the local network of entrepreneurial start-ups (Leuven.inc, see section B.2). The funding base gradually increased thanks to support from the local government for the student incubator activities, which was followed by support from private sources. Currently, the annual budget is around $€ 200000$ (excluding in-kind 'staff time' contributions) and is set to increase in the future.

Besides access to its research base and incubation funding, the university also provides significant support to its entrepreneurial projects via access to infrastructure and networks. Especially for student-led ventures, one of the most valued support instruments is access to facilities such as meeting rooms and workplaces. It was decided to provide facilities for student-entrepreneurs in a decentralised way, across the various campuses. The facilities include

37 See e.g. the LERU paper 'Student entrepreneurship at research-intensive universities: From a peripheral activity towards a new mainstream' (https://www.leru .org/publications/student-entrepreneurship-at-research-intensive-universities-from-a -peripheral-activity-towards-a-new-mainstream). 
a so-called 'fab lab', providing students with the necessary prototyping tools. In addition, students interested in entrepreneurship get access to a creativity lab where they can meet and work on their business plan. Furthermore, students intending to start an entrepreneurial venture can get office space at an incubator facility that is shared with young start-up companies so that they can come into contact with peer entrepreneurs.

In order to support the further growth of its spin-offs and to leverage the entrepreneurial ecosystem, KU Leuven has also invested substantially in its own science parks, business centres and incubators since the mid-1990s. This resulted in the so-called Leuven Technology Corridor ${ }^{38}$ consisting of science parks at several locations both in the immediate vicinity of Leuven (cities of Termunck, Arenberg and Haasrode) and further afield (Genk, Tienen).

The KU Leuven science parks play an important role in attracting foreign investments as well as research capabilities. Noteworthy examples are Huawei, ${ }^{39}$ which established its European Research Institute in Leuven in 2015, and the Japanese multinational Nitto Denko Corporation ${ }^{40}$ which moved the location of its European Headquarters to Leuven in 2016, both citing the talent pool in the vicinity of the university as a key factor in their decision.

Internationalisation is also an important aspect of the university's policy. In that respect, initiatives have been taken to support the internationalisation process of new ventures that originate from the Leuven ecosystem. Especially relevant for entrepreneurial projects is the fact that the university is a founding member of the BelCham ${ }^{41}$ incubators in New York and San Francisco. ${ }^{42}$ In this way, KU Leuven-based projects have direct access to the US market and get local support from the Belcham staff.

\footnotetext{
https://lrd.kuleuven.be/en/hitech/science-parks-and-business-centres.

$39 \mathrm{https} / /$ china.diplomatie.belgium.be/fr/actualites/huawei-announces-launch-its -european-research-institute-eri-leuven.

$40 \mathrm{https} / / /$ www.leuveninc.com/event/36/4939/Japanse_multinational_Nitto_Denko _Corporation_vestigt_haar_Europees_hoof/.

${ }_{41} \mathrm{https} / / /$ www.belcham.org/atelier/-the Belgian-American Chamber of Commerce is a not-for-profit organisation with the purpose of supporting Belgian excellence in the United States.

42 The Belgian-American Chamber of Commerce, is a not-for-profit organisation with the purpose of supporting Belgian excellence in the United States.
} 


\section{B.6 VISION AND STRATEGY FOR THE NEAR FUTURE}

In 2018, KU Leuven presented its new strategic plan, based on the following five pillars:

- Truly International - the transition from a national university with a global reputation to a truly international university;

- Future-oriented education - the choice for a future-oriented teaching model based on activation and a corresponding structure of the academic year;

- Going digital - the use of educational technology in a way that facilitates collaborative learning and multi-campus education, and broadens the international reach;

- Interdisciplinarity - the development of an interdisciplinary dialogue in addition to disciplinary depth in education, research and public outreach;

- Sustainability - the choice for sustainable management and a commitment to the Sustainable Development Goals in research and education.

A distinctive aspect of the strategic plan is that the five pillars purposefully do not fit within a single policy domain but each of them impacts multiple aspects of the university. Besides the attention it receives in the new strategic plan, interdisciplinarity has been a common theme in the university's governance in the past, as highlighted by, for example, the research centres and LRD divisions, the governance of student entrepreneurship (e.g. the PiP projects, the composition of the Lcie Academy steering committee) and incubation instruments like CD3. Nevertheless, interdisciplinary initiatives and platforms at the university are considered to be still too limited in number and not visible enough, hence the strategic plan aims to further advance interdisciplinary dialogue in the three missions of the university. In that respect, the university envisages to recognise large-scale interdisciplinary platforms as 'institutes', to provide their work on long-term goals and their approach with a more distinctive profile. Examples are the aforementioned Leuven Brain Institute and the Leuven Cancer Institute..$^{43}$ Besides fostering scientific interaction as such, interdisciplinarity is also crucial for establishing serendipitous connections of a more entrepreneurial nature across domains. In this sense, the increased support for interdisciplinarity complements existing networking initiatives like Leuven Mindgate (section B.2).

Another governance principle that will continue to guide KU Leuven is the decentralisation of decision-making, coupled with centralised support

43 https://www.uzleuven-kuleuven.be/lki/en. 
mechanisms. The LRD research divisions discussed in section B.4 are set up by researchers as autonomous vehicles for their technology transfer activities but receive professional support from the university's centralised TTO services. As another example of how decentralised incentives are coupled with efficiency-enhancing centralisation, the Leuven Community for Innovation driven Entrepreneurship coordinates the various entrepreneurship initiatives but is at its heart a student-driven and student-owned initiative.

Also in the future KU Leuven will continue to develop and grow novel platforms and instruments that can further support and enhance the translation of research results into products and services for societal benefit. 